\title{
The Impact of Management Information Systems on the Financial Performance of Islamic Banks in Jordan-Jordan Islamic Bank: A Case Study
}

\author{
Ameen B. Al-Basheer ${ }^{1} \&$ Hisham A. Shtanawi ${ }^{1}$ \\ ${ }^{1}$ Ajalon National University, Ajalon, Jordan \\ Correspondence: Ameen B. Al-Basheer, Ajalon National University, Ajalon, Jordan. E-mail: \\ ameen981@gmail.com
}

Received: July 10, 2015

Accepted: August 6, 2015

Online Published: September 18, 2015

doi:10.5539/ijbm.v10n10p143

URL: http://dx.doi.org/10.5539/ijbm.v10n10p143

\begin{abstract}
This study aims to analyze the impact of management information systems on the financial performance of the Islamic banks and the Jordan Islamic Bank was selected as a case study for these banks. In order to achieve the objectives of this study, it was used the descriptive analytical method by using a questionnaire developed to identify and ensure its credibility and validity, and the study came up with some results including: that there is a statistically significant effect between information systems and dimensions represented in speed of achievement, and the simplification of procedures and information security and between financial performance and between financial performance represented in profitability and market share.
\end{abstract}

Keywords: management information system, financial performance, Islamic banks, Jordan

\section{Introduction}

The reliance on systems and information technology has become an important tool of good management of business organizations tools, and this is in order to achieve its objectives and decision-making at various levels to be the pillars of the organization's ability to compete today's business environment, especially the rapid development of information systems has significantly affected the work of organizations as well as developing its services as an integrated system that combines information and information systems, and all that came with the aim of achieving the goals of these organizations in terms of achieving the greatest profit, and maintaining the market share of these organizations in light of the strong competition between them, so, this research was to study the impact of management information systems that are represented in three dimensions which are: speed of achievement, the simplification of procedures, and information security of the financial performance of these organizations represented in profitability and market share.

\subsection{The Study Problem}

The problem of the study is to state the role of management information systems represented in the speed achievement, information security, the simplification of procedures, and to raise the efficiency of the financial performance of Islamic banks in Jordan - Jordan Islamic Bank - a case study.

\subsection{Importance of the Study}

The importance of the study came from the important question regarding the impact of management information systems on the financial performance of Islamic banks of Jordan, where the management information systems enter in all areas of the work of these banks in terms of speed of achievement, the simplification of procedures, and the provision of security information, and which actively influence the management decisions through the information they provide, and their impact on the decision-making process, also they have an impact on customers' decisions in dealing with these Islamic banks, and thus, the significance of this study comes through its attempt to search the extent of the impact of information systems on the financial performance of these banks.

\subsection{Hypotheses of the Study}

The study first addresses the problem through the main hypothesis of the following:

There is no statistically significant relationship between management information systems and financial 
performance (profitability, market share) in Islamic banks.

This hypothesis has come up with the following sub-major assumptions:

1) There is no statistically significant relationship between the speed of achievement and financial performance of Islamic banks in Jordan.

2) There is no statistically significant relationship between simplifying procedures of workand the financial performance of Islamic banks in Jordan.

3) There is no statistically significant relationship between the system's ability to provide information security and financial performance in the Jordanian Islamic banks.

\subsection{Questions of the Study}

This study attempts to answer the following questions:

1) What is the effectiveness of the speed of achievement on the financial performance of Islamic banks in Jordan.

2) What is the effectiveness of simplifying the procedures of work of the financial performance of Islamic banks in Jordan procedures.

3) Does the system's ability to provide information security have an impact on the financial performance of Islamic banks in Jordan.

\subsection{The Study Sample}

\section{Independent variable}

Speed of achievement

Simplification of procedures

Information security

\subsection{Method of Data Collection}

The study relied on the following sources:

1) Primary sources: they deal with the collection of information by a special questionnaire for this purpose, and analyze this information to answer these questions and test the validity of hypotheses.

2) Secondary Sources: they deal with references and resources available in libraries, including books, articles, studies, and theses.

\section{Previous Studies}

Omari (2012) has conducted a study entitled: The impact of information systems resources on achieving competition: studying a case of telecom security company: This study aimed to study the impact of information systems resources in achieving competitive strategies for a security company for mobile communications in the Jordanian market, and the sample of the study was randomly selected. Moreover, the data was analyzed by using the Statistical Package for the Social Sciences (SPSS), and the study found a range of results including:

1). Provide a high level of system resources in a security company of hardware and software, followed by human resources and networks.

2). The level of innovation came in high level among competition strategies of security company whereas it came low to other strategies.

Abdul Qadir (2011) has conducted also a study entitled: The role of strategic information to strengthen the competitive advantage: Algerian institutions:

The study aimed to assess the role of strategic information systems to strengthen the competitive advantage in the Algerian institutions and support phases of decision-making, particularly with regard to human resources, and the study came up with the following results:

1). The degree of availability of Information System properties, which are applicable when making strategic decisions, was medium in Algerian institutions.

2). The components of applicable information system in some Algerian institutions do not significantly contribute to the strategic decisions, because the contained database of applied system is not characterized by the ability to storage, retrieval and distribution. 
The study conducted by Tashtosh (2010) entitled: The role of information systems in the capacity of storing strategies for competitive advantage in the Jordanian industrial organizations:

The study aimed to try to choose the role of information systems in achieving competitive advantage through differentiation strategies and reduce cost, the study concluded some results, including:

There is a strong positive relationship between information systems and competitive advantage by using the recommended training programs to achieve differentiation and to assess the relationship between information systems and human resources for the purposes of development and updating information systems.

The study conducted by Petter, DeLone and McLean (2013) entitled: Information System Success: The Quest for The Independent Variables:

It was reviewed the literatures which dealt with the independent factors that affect the success of the information system that examined more than 600 previous studies, the results of the study found about (15) factors affecting the success of information systems and these factors are: Enjoyment, confidence, expectations of the user, external stimulation, infrastructure of information technology, the consistency of the task, the difficulty of the task, trends toward technology, regulatory role, user participation, relationship with the developers, the field of cognitive experience, management support, process of management, and organizational efficiency.

The study conducted by Kaur and Aggrawal (2013) entitled: Exploration of Success Factors of Information System: This study made a survey to the literatures relevant to the factors of information systems success, in order to propose a good sample for the factors related to the success of these systems. The study recommended to develop a sample to ensure the most important success factors, namely: factors related to human resources, followed by special factors of planning, then factors related to implementation, and finally factors related to continuous updating and evaluation of the system.

The study conducted by Chan (2009) entitled: The Roles of User Motivation to Perform A Task and Decision Support System (DSS) Effectiveness and Efficiency in DSS Use: The aim of this study is to obtain actual measurements to measure systems of decision support using three elements, as well as to know the motives that make users perform their functions and test how to interact with characteristics of decision support systems, the study found that individuals who used the decision support systems are more effectively to perform their motivated tasks with the best image, The study found that there are various differences between two of used scales which are time and steps, and the results showed that the use of decision support systems is significantly increasing and the interest of using decision support systems was high.

\subsection{Theoretical Framework}

The concept of management information system (MIS) is defined as:

A set of overlapping or interacting elements with each other that work on different types of data and information, and work on processing, storing, transmitting and distributing them to the beneficiaries for the purpose of decision support, as well as providing control on the organization process, additionally, the information system analyzes the problems, and identify appropriate alternatives to solve them. Moreover, it provides database for the activities of organization and the surrounding environment to support decision-makers (Krajewski, 2005).

As for Al-Azzawi (2011), he defined management information systems as a group made up of individuals and devices, which holds the processes of collecting, processing, and storing data, in addition to retrieve them in order to emphasize the accuracy of decision-making through meeting the needs of information managers at the right time and great effectiveness."

whereas (Al-Ali, 2006) has defined it as: "business systems that address the business designed to address capturing, broadcast, conversion, storage, processing, and display information that supports other business systems."

As for Haag et al. (2002) and others, they defined it as "planning for development, and the use of information technology tools to help employees in doing with tasks related to data and management processing".

Hamidi et al. (2005), defined management information systems as a systematic computerized system that is capable of collecting data with a view to providing it for decision-making. Also, they defined it as "an organized group of individuals and devices (Hardware), (Software), communication networks (Network), and sources of information that collect information to be distributed within the organization" (O'Brien, 2003, p. 7).

Information technology also was defined as "a set of interrelated elements that collect, process, store, and distribute information to support decision-making, and control in the organization, and analysis of problems, in addition to complicated topics by the workers and the production of new products" (Laudon, 2007, p. 7). 
It is noted from the concepts mentioned above that these concepts are complex and include extras in terms of its dimensions and members, and the researcher will choose a procedural concept to measure the procedural items in the fourth chapter.

\subsubsection{The Main Elements of Information Systems}

Management Information System contains a number of key elements, namely:

A. Input/ data: it includes the entry of data from internal or external sources, and it must take into account the accuracy in data entry operations, because the lack of precision will lead to erroneous results which will affect the nature of the system outputs, the process of data entry occurs by appropriate entry means, and the keyboard, mouse or scanner are in the forefront.

B. Processing: it means processing the incoming data and turns it into understandable and usable information, and the processing part of computer system is the brain.

C. Output: it includes information that has been processed, and transferred from the CPU to the appropriate output means such as a computer screen, or printer ... etc.

D. Feedback: The information, that has been taken out in the form of informative reports, makes the system receives the views of users, or decision-makers about their suitability for their information needs, or it may re-entry to the system as inputs for the purposes of further process.

\subsubsection{Types and Functions of Management Information Systems}

Many researchers in the area of administrative literature reported different classifications of Management Information Systems, McLeod classified the information systems in two general systems. (McLeod, 1990):

First: MIS: Management Information System

These systems provide specialized information, to assist the process of administrative decisions, and this goal can be achieved through the following sub-systems consisting of this system:

\section{1). Executive Information Systems:}

These systems provide the senior management with strategic information, which are easy to operate, understand and use, in addition to the use of illustrations dramatically.

2). Decision Support Systems:

These systems are concerned with providing direct support to decision makers; and this is by providing samples of decision-making, and databases, which are geared towards making un-programmed, or semi-programmed decisions, these systems provide answers about potential consequences of each alternative to be chosen by the decision maker.

\subsubsection{Information Reporting System}

These systems are designed to provide the ultimate beneficiary, or decision-makers with reports contain information to support daily decisions-making, and the data sources of these systems are derived from the internal environment of the regulation-making process.

\section{Second: Operations Information System}

These systems specialize in running data of processes that take place in the organization, and this can be through the following sub-systems:

\section{1) Office Automation Systems:}

These systems support the productivity of offices and communication, so they are working on data collection, processing, storage and transferring, they are also working on formats of electronic information transfer such as: word processing, e-mail, and teleconferencing ... etc.

2) Control systems operations Process Control System:

The field of these systems is the operational decisions systems that control the natural processes of organization, where these decisions are stereotypical, or programmed; thus, the computer can perform it, Examples include: control systems used in oil refineries.

3) Transaction Processing System data conversion systems:

It deals with running and recording data of the results of conversion processes within the organization, it is also responsible for updating databases. This is in addition to that there is another classification of management 
information systems, consisting of a set of other subsystems, as stated by (O'Brien, 1990):

Expert System: These systems provide specialized advice and solutions to the problems of a particular area. These systems have come as a product of the work in the field of artificial intelligence which is defined as behavior that played by the machine, which is such as intelligence or human performance.

(B) End User Computing System: it provides direct support to the final beneficiaries, in operational and administrative levels.

(C) Strategic Information System: It is designed to achieve the strategic objectives of the organization and to senior management in the long run.

(D) Function Information System: It provides support for various functions in the organization as marketing jobs, production and finance.

Management information systems are classified based on different criteria that must meet the following requirements:

1). Receiving different data.

2). Processing data.

3). transmitting information to users.

4). Help the various administrative levels in responsible decision-making, and decisions are classified as follows:

A-Programmable decisions: permanent routine ones.

B-Semi- programmable decisions: they make decisions that relate to the issues which are specific and defined and the other part is indefinite.

C-Non-programmable decisions: they are decisions concerning in issues which lack the availability of information, and rely on the experience of the decision maker.

5). Exchanging information between administrative units: There are a range of administrative information of interest to institutions and are intended to serve all levels of management systems, which are:

(A) Transaction processing systems: They provide basic data that represents an important input to the other administrative information systems.

(B) Management reporting systems: They are supported by the administrative decisions of cases in which the structure is stable with united variables that provide the necessary management information.

(C) Decision support systems: the management systems help in making decisions about the rare occurrence of cases, and that can be resolved by artificial intelligence, such as workforce development and forecasting.

(D) Support systems managers: the managers who help in obtaining the necessary information for the workflow.

(E) Support the work groups systems: such systems help all employees while performing their daily activities and provide them with the possibility of communication between workers inside and outside the organization and this is through: e-mail and fax to transfer images and electronic data interchange.

(F) Expert systems: They store information in the form of facts, and the rules in the database, and one can take advantage of them by using them at any time as any other business, and comparing them to similar problems of stored cases.

\subsection{Financial Performance}

Performance is defined as "a reflection of the ability of the organization and its ability to achieve its objectives" (Eccles, 1991, p. 131) and it is also defined as a "reflection of how the organization uses human and financial resources and how to exploit them in order to achieve its goals (Robins \& Wiersema, 1995). Moreover, it is defined by (Miller \& Bromiley, 1990) as the organization's ability to achieve long-term goals".

Thus, using the financial performance is the common denominator between writers, researchers and managers, whether within applied or theoretical studies inthe processes of evaluating performance practically in various business organizations. (Lynch, 2003, p. 374) stated that financial performance will remain the fixed scale for the success of organizations, as well as the lack of financial performance of organizations with basic required level, will threaten their existence and continuity. Additionally, some writers went beyond that to emphasize the importance of financial performance, since it is the most important objective of the organization, and within this trend, both of (Hunt \& Morgan, 1995, p. 6) see that the superior financial performance is the goal of the primary organizations, and he secondary objectives of the organization can be achieved implicitly through the 
achievement of superior financial performance.

The importance of using ratios and financial indicators in measuring the performance of organizations lies in their ability to show the important aspects of financial and competitive position of the organization, and go all of their study in (Thompson \& Strickland, 1999, pp. 104-105) said that the organization whose financial ratios indicate to a weak performance, they should reconsider their current strategies, and in the same context, (David) sees in his study that the most commonly used quantitative criteria in assessing the performance of strategies are financial ratios (David, 2001, p. 309).

These financial ratios are divided into groups, each one is focusing on a particular financial and performance aspect, and these groups are:

Profitability ratios: the ratios that measure the efficiency and effectiveness of the Organization's management to generate profits through the use of its assets efficiently.

Liquidity ratios: it is a group of ratios to measure the organization's ability to meet its short-term obligations (Abdullah Ahmed Abdullah Da'as, 2010, p. 98).

As for (Macmenamin, 1999, pp. 323-324), he says that relying on financial ratios only in the assessment of financial performance gives a non-dimensional vision about the organization, so you should promote this method in measuring non-financial performance standards for building an effective measure for the performance of the organization, and within this trend, (Holbech, 2005, p. 23) believed that if the manager interested in the comprehensive and overall performance of the organization, it would be more inclined to find a balance between operational and financial concerns, so in addition to the indicators and financial ratios, the performance relies on standards and operational indicators in the market share, and introducing new products, and quality of products / presented service, in addition to the effectiveness of marketing operations and productivity, and other metrics related to the level of performance of the organization's operations. in case the performance measures were included in operational standards, it can be shown the image of management of performance that financial indicators can detect.

\section{Statistical Analysis and Testing Hypotheses}

Amendment scale:

For data analysis and validation of hypotheses have been relying on a scale Likert Quintet in to answer questions, according to the following class: degree (1) reflects the strongly disagree, degree (2) reflects not agree, degree (3) reflects the neutral, degree (4) express agree, degree (5) reflect strongly agree, and interpretation of averages to estimate the study sample on each paragraph of the resolution and on each of the fields; was used standard statistical follows and shown in Table (1):

For data analysis and testing hypotheses, it was used the scale of Likert Quintet to answer questions, according to the following class: degree (1) reflects the strongly disagree, degree (2) reflects disagree, degree (3) reflects neutral, degree (4) reflects agree, degree (5) reflect strongly agree, and the interpretation of averages to estimate the study sample for each item of the questionnaire, it was used the statistical standard follows as shown in Table 1.

Table 1. Statistical standard

\begin{tabular}{llllll}
\hline Degree & $\mathbf{1}$ & $\mathbf{2}$ & $\mathbf{3}$ & $\mathbf{4}$ & $\mathbf{5}$ \\
\hline Level of agreement & Strongly disagree & disagree & Neutral & Agree & Strongly agree \\
\hline
\end{tabular}

With regard to the limits adopted in this study, when commenting on the arithmetic mean of the variables contained in the study sample. To determine the degree of agreement, the researcher has identified three levels (high, medium, low) based on the following equation:

Length of period $=$ (upper limit of alternative- Minimum limit of alternative $) /$ number of required levels.

$(5-1) / 3=4 / 3=1.33$ and thus the levels are as follows:

Low degree of agreement: from 1- less than 2.33 .

Medium degree of agreement: from 2.34-less than 3.67.

High degree of agreement: from 3.68- 5. 


\subsection{The Study Sample}

The researcher has randomly distributed (115) questionnaires on Islamic banks staff. After reviewing the questionnaires to make sure of the validity of analysis, he took (105) of them back because he found out that (5) questionnaires are not valid for statistical analysis either for the lack of seriousness or for the lack of completing data, and therefore the study sample consisted of (100) male and female employees in Islamic banks, Table 2 shows the distribution of respondents depending on personal variables.

Table 2. The distribution of the study sample depending on personal variables of $(n=100)$

\begin{tabular}{|c|c|c|c|}
\hline Variables & Level & Repetition & Percentage \\
\hline \multirow{5}{*}{ Age } & Less than 30 & 20 & 20.0 \\
\hline & $30-40$ years & 35 & 35.0 \\
\hline & $41-50$ years & 30 & 30.0 \\
\hline & 51 years and above & 15 & 15.0 \\
\hline & Total & 100 & 100.0 \\
\hline \multirow{3}{*}{ Gender } & Male & 85 & 85.0 \\
\hline & Female & 15 & 15.0 \\
\hline & Total & 100 & 100.0 \\
\hline \multirow{5}{*}{ Educational level } & $\mathrm{BA}$ & 74 & 74.0 \\
\hline & High Diploma & 14 & 14.0 \\
\hline & Master & 10 & 10.0 \\
\hline & $\mathrm{phD}$ & 2 & 2.0 \\
\hline & Total & 100 & 100.0 \\
\hline \multirow{7}{*}{ Specification } & Accounting & 42 & 42.0 \\
\hline & Business management & 25 & 25.0 \\
\hline & Economy & 12 & 12.0 \\
\hline & Financial sciences & 13 & 13.0 \\
\hline & Computer & 4 & 4.0 \\
\hline & Others & 4 & 4.0 \\
\hline & Total & 100 & 100.0 \\
\hline \multirow{5}{*}{ Years of experience } & Less than 5 years & 26 & 26.0 \\
\hline & $6-10$ years & 24 & 24.0 \\
\hline & $11-15$ years & 33 & 33.0 \\
\hline & 16 years and above & 18 & 17.0 \\
\hline & Total & 100 & 100.0 \\
\hline \multirow{5}{*}{ Management level } & Employee & 76 & 76.0 \\
\hline & Supervisor & 12 & 12.0 \\
\hline & Head of dept. & 10 & 10.0 \\
\hline & Manager & 2 & 2.0 \\
\hline & Total & 100 & 100.0 \\
\hline
\end{tabular}

Table 2 shows the following:

1). The highest percentage for the distribution of the study sample depending on the variable of age was (35.0\%) for the age (30-40 years), while the lowest percentage was (15.0\%) for the age (51 years and above).

2). The percentage of males in the sample was $(85.0 \%)$, while the percentage of females was $(15.0 \%)$.

3). The highest percentage for the distribution of the study sample depending on the level of education variable was $(74.0 \%)$, for $(\mathrm{BA})$ level, while the lowest percentage was $(2.0 \%)$, for the educational level $(\mathrm{PhD})$.

4). The highest percentage for the distribution of the study sample depending on the variable of specialization was $(42.0 \%)$ for (accounting), while the lowest percentage was $(4.0 \%)$ for specialization of (computer, others).

5). The highest percentage for the distribution of the study sample depending on the years of experience was $(33.0 \%)$ for the experience (from 11-15 years), while the lowest percentage was (17.0\%) for the experienceof (16 years and above). 
6). The highest percentage for the distribution of the study sample depending on the variable of administrative level was $(76.0 \%)$ for the administrative level (employees), while the lowest percentage was $(2.0 \%)$ for the administrative level (manager).

\subsection{The Tool Reliability}

To check out the reliability of the scale, the researcher has used the (Test-Retest) approach and applying it on an exploratory sample consisting of 10 employees from outside the study sample twice within a timeframe of two weeks, moreover, the correlation coefficient was figured out by using the Pearson Correlation coefficient among their estimates in both times to the general study tool, the correlation coefficient of the two applications reached (0.85), which is a statistically significant at the level of significance $(=0.05)$. It was also used Cronbach Alpha. Table 3 shows the reliability coefficient, Pearson correlation coefficient, it can be seen from the table that the reliability factor was $(0.83)$, which is high and acceptable value for the purposes of the application.

Table 3. The reliability coefficient (Cronbach's alpha) and Pearson correlation coefficient

\begin{tabular}{llll}
\hline \multirow{2}{*}{ Fields } & Dimension & Cronbach's alpha & $\begin{array}{l}\text { Pearson } \\
\text { coefficient }\end{array}$ \\
\hline \multirow{3}{*}{$\begin{array}{l}\text { Management } \\
\text { systems }\end{array}$} & The system's ability to provide information & 0.84 & $0.86^{*}$ \\
& security & 0.82 & $0.85^{*}$ \\
& Speed of achievement & 0.81 & $0.84^{*}$ \\
Financial performance & Simplifying work procedures & 0.83 & $0.85^{*}$ \\
& Dimension as a whole & 0.82 & $0.84^{*}$ \\
The tool as a whole & Profitability & 0.83 & $0.83^{*}$ \\
\hline
\end{tabular}

Statistically significant at the level of significance (0.05).

\subsection{Presenting the Results of Statistical Analysis and Testing the Hypotheses of Study}

Here are the results of the statistical analysis and testing the hypotheses of the study, which aimed to identify "the impact of management information systems on the financial performance of Islamic banks".

-First: The results related to the arithmetic means of answers of the study sample for the field of "the effectiveness of information systems dimensions."

The arithmetic means and standard deviations for the answers of questionnaires for the field of "the effectiveness of information systems" and the dimensions of the field as a whole, Table 4 illustrates this.

Table 4. Arithmetic means and standard deviations for answers of the field "effective information systems" and the area as a whole $(\mathrm{n}=100)$

\begin{tabular}{llllll}
\hline Rank & Number & Dimension & Arithmetic means & Standard deviation & Level of evaluation \\
\hline 1 & 2 & Speed of achievement & 4.18 & 0.62 & High \\
2 & 1 & The system's ability to provide information security & 4.07 & 0.62 & High \\
3 & 3 & Simplification of work procedures & 3.98 & 0.58 & High \\
\multicolumn{2}{l}{ The areas as a whole } & 3.84 & 0.47 & High \\
\hline
\end{tabular}

Table 4 shows that the arithmetic mean of the answers regarding the dimensions of the effectiveness of information systems field ranged between (3.98-4.07) with a high degree of evaluation for all-dimensions, it came in the first rank after the field of "speed of achievement" with a mean (4.185), which was ranked as the second after "the system's ability to provide information security" with a mean (4.07), and in the third and final rank, it was the field of "Simplifying work procedures" with a mean (3.98), and the arithmetic average of the field as a whole was (3.84) and with a high degree of evaluation, and thus, this effectively indicates the presence of interest in information systems in Islamic banks. 
The arithmetic means and standard deviations were figured out for the answers of the study sample to all items of the field related to the effectiveness of information systems at all dimensions, tables (5-7) illustrate that.

Table 5. Arithmetic means and standard deviations for the answers of study sample for items of the system's ability to provide information security.

\begin{tabular}{|c|c|c|c|c|c|}
\hline Rank & No. & Items & Average & $\begin{array}{l}\text { Standard } \\
\text { deviation }\end{array}$ & $\begin{array}{l}\text { Degree of } \\
\text { evaluation }\end{array}$ \\
\hline 1 & 2 & Deterrent sanctions taken against those leaking information illegally. & 4.33 & 0.92 & High \\
\hline 2 & 1 & $\begin{array}{l}\text { Provide adequate protection and software necessary for the protection of } \\
\text { software and hardware from damage and vandalism. }\end{array}$ & 4.29 & 0.75 & High \\
\hline 3 & 3 & Control inputs very effectively. & 4.13 & 0.90 & High \\
\hline 4 & 4 & $\begin{array}{l}\text { The system used in the bank is characterized with high efficiency in the } \\
\text { (storage, classification }\end{array}$ & 3.92 & 1.02 & High \\
\hline 5 & 5 & Control workers with private systems & 3.67 & 0.87 & High \\
\hline \multicolumn{3}{|c|}{ Dimension as a whole } & 4.07 & 0.62 & High \\
\hline
\end{tabular}

It is noted from Table 5 that the arithmetic mean of the answers related to the dimension of the system's ability to provide information security ranged between (3.67-4.33) with a high degree of evaluation for all items, where it was ranked as the first (2), which states "take sanctions deterrent against those leaking information illegally" with a mean (4.33), and it was ranked in the last place number (5), which states" using controls on workers through special regimes "with a mean (3.67), and the arithmetic average of the dimension as a whole (4.07) with a high degree evaluation.

Table 6. Arithmetic means and standard deviations for the study answers for items of the speed of achievement

\begin{tabular}{|c|c|c|c|c|c|}
\hline Rank & No. & Items & Average & $\begin{array}{l}\text { Standard } \\
\text { deviation }\end{array}$ & $\begin{array}{l}\text { Degree of } \\
\text { evaluation }\end{array}$ \\
\hline 1 & 1 & $\begin{array}{l}\text { Performance of work has become faster with management } \\
\text { information system }\end{array}$ & 4.33 & 0.56 & High \\
\hline 2 & 4 & $\begin{array}{l}\text { Management information systems eased the communication among } \\
\text { branches and reduced time spent on transactions }\end{array}$ & 4.25 & 0.79 & High \\
\hline 3 & 2 & $\begin{array}{l}\text { Management information systems made an integration and } \\
\text { consistency between branches faster. }\end{array}$ & 4.21 & 0.78 & High \\
\hline 3 & 5 & E- services increased the number of customers. & 4.21 & 1.06 & High \\
\hline 5 & 3 & $\begin{array}{l}\text { Management information systems provided enough time for higher } \\
\text { management to take decisions. }\end{array}$ & 3.92 & 1.14 & High \\
\hline \multicolumn{3}{|c|}{ Dimension as a whole } & 4.18 & 0.62 & High \\
\hline
\end{tabular}

Table 6 shows that the arithmetic mean of the answers for the items related to the speed of achievement ranged between (3.92-4.33) with a high degree of evaluation for all items, this domain was ranked the first in item (1) which states that "using information systems has developed the performance of work to be faster" and the mean was (4.33). as for the last rank, it was for item (3), which states "administrative information provides senior management system with enough time to take decisions", with a mean (3.92), and the mean was for after the domain as a whole (4.18) and with a high degree of evaluation. 
Table 7. Averages and standard deviations for the study sample answers for the item of" simplifying work procedures

\begin{tabular}{|c|c|c|c|c|c|c|}
\hline Rank & No. & Items & Average & $\begin{array}{l}\text { Standard } \\
\text { deviation }\end{array}$ & $\begin{array}{l}\text { Degree } \\
\text { evaluation }\end{array}$ & of \\
\hline 1 & 4 & Management information systems can coordinate business. & 4.08 & 0.88 & High & \\
\hline 2 & 3 & $\begin{array}{l}\text { Management information systems eased information access to } \\
\text { employees. }\end{array}$ & 4.04 & 1.08 & High & \\
\hline 3 & 5 & $\begin{array}{l}\text { Management information systems can store and retrieve information } \\
\text { easily. }\end{array}$ & 4.00 & 0.98 & High & \\
\hline 4 & 1 & Management information systems eliminated routine. & 3.88 & 0.95 & High & \\
\hline 5 & 2 & $\begin{array}{l}\text { Management information systems eliminated the repetition of paper } \\
\text { transactions and storage space. }\end{array}$ & 3.87 & 0.99 & High & \\
\hline \multicolumn{3}{|c|}{ Dimension as a whole } & 3.98 & 0.58 & & High \\
\hline
\end{tabular}

Table 7 shows that the arithmetic mean of the answers for the item of "simplifying work procedures" ranged between (3.87-4.08) with a high degree of evaluation for all items of the domain, item number (4) came in the first rank which provides that "information systems can coordinate between the business" with a mean (4.08), whereas item number (2) came in the last rank which states that" the information systems reduced repeated paper work or storage space" with a mean (3.87), and the arithmetic average was for the domain as a whole (3.98) with a high degree of evaluation.

-Second, the results relating to the mean of study sample's answers for the field of "financial performance dimensions."

The arithmetic means and standard deviations for the answers of the field "financial performance" were figured out for the dimensions of the field as a whole, Table 8 shows that.

Table 8. Arithmetic means and standard deviations for the answers of "financial performance" domain and the field as a whole $(\mathrm{n}=100)$

\begin{tabular}{llllll}
\hline Rank & No. & Dimension & arithmetic means & standard deviations & Degree of evaluation \\
\hline 1 & 1 & Profitability & 3.91 & 0.63 & High \\
2 & 2 & Market share & 3.73 & 0.53 & High \\
\multicolumn{2}{l}{ Domain as a whole } & & 3.82 & 0.50 & High \\
\hline
\end{tabular}

Table 8 shows that the arithmetic mean of the answers for the dimensions of financial performance field ranged between (3.73-3.91) with a high degree of evaluation, the domain of "profitability" came in the first rank with a mean (3.91), and the second rank was for the domain of "market share" with a mean (3.73), and the arithmetic mean was for the field as a whole (3.82) with a high degree of evaluation.

The arithmetic means and standard deviations of the answers of the study sample for all items of the field "financial performance" separately. Tables (9-10) show that.

The arithmetic means and standard deviations of the answers of the study sample for the items of all dimensions of "financial performance" field separately, tables (9-10) shows that. 
Table 9. The arithmetic means and standard deviations of the answers of the study sample for the items of "profitability"

\begin{tabular}{|c|c|c|c|c|c|}
\hline Rank & No. & Items & Average & $\begin{array}{l}\text { Standard } \\
\text { deviation }\end{array}$ & $\begin{array}{l}\text { Degree } \\
\text { evaluation }\end{array}$ \\
\hline 1 & 5 & $\begin{array}{l}\text { Management information systems reduce the cost of the } \\
\text { presented service. }\end{array}$ & 4.00 & 0.93 & High \\
\hline 2 & 1 & $\begin{array}{l}\text { Management information systems reduce the payment of } \\
\text { compensation for customers against dangers. }\end{array}$ & 3.92 & 1.10 & High \\
\hline 2 & 4 & $\begin{array}{l}\text { Management information systems reduces the cost by } \\
\text { maintaining the profitable customers }\end{array}$ & 3.92 & 0.83 & High \\
\hline 4 & 2 & $\begin{array}{l}\text { Management information systems reduce the percentage of } \\
\text { compensation for customers when they face danger. }\end{array}$ & 3.88 & 0.85 & High \\
\hline 5 & 3 & $\begin{array}{l}\text { Management information systems contribute to quick } \\
\text { response. }\end{array}$ & 3.83 & 0.92 & High \\
\hline \multicolumn{3}{|c|}{ Dimension as a whole } & 3.91 & 0.63 & High \\
\hline
\end{tabular}

Table 9 shows that the arithmetic mean of answers for the items of "profitability" dimension ranged between (3.83-4.00) with a high degree of evaluation, the item number (5) came in the first rank which states that " the management information systems can reduce the cost of service presented to customers" with a mean (4.00), whereas the item number (3) which states that "management information systems contribute to respond quickly to customers compared to what provided by competitors of similar responses", with a mean (3.83), and the arithmetic means of the dimension as a whole was ( 3.91 ) with a high degree of evaluation.

Table 10. The arithmetic mean and standard deviations for the answers of the study sample to the "market share" domain

\begin{tabular}{|c|c|c|c|c|c|c|}
\hline Rank & No. & Items & Average & $\begin{array}{l}\text { Standard } \\
\text { deviation }\end{array}$ & $\begin{array}{l}\text { Degree } \\
\text { evaluation }\end{array}$ & of \\
\hline 1 & 1 & $\begin{array}{l}\text { Management information systems used in knowing } \\
\text { the shares of competitors customers }\end{array}$ & 4.00 & 0.98 & High & \\
\hline 2 & 2 & $\begin{array}{l}\text { Management information systems used in knowing } \\
\text { competitors' actions to customers }\end{array}$ & 3.88 & 0.80 & High & \\
\hline 3 & 3 & $\begin{array}{l}\text { Management information systems used in knowing } \\
\text { the bank's ability to acquire new customers. }\end{array}$ & 3.79 & 0.78 & High & \\
\hline 4 & 4 & $\begin{array}{l}\text { Management information systems used in knowing } \\
\text { the change of market share in banks depending on } \\
\text { competitors }\end{array}$ & 3.54 & 1.02 & Medium & \\
\hline 5 & 5 & $\begin{array}{l}\text { Management information systems used in knowing } \\
\text { the market opportunities to promote the } \\
\text { competitive advantage. }\end{array}$ & 3.46 & 1.02 & Medium & \\
\hline \multicolumn{3}{|c|}{ Dimension as a whole } & 3.73 & 0.53 & High & \\
\hline
\end{tabular}

Table 10 shows that the arithmetic mean of the answers to the items of the market share dimension ranged between (3.46-4.00), where item number (1) which states that "management information systems enable to know the competitors share of customers" with a mean (4.00) and a high degree of evaluation, the item number (5) which states that "the management information systems enable the bank to analyze the market opportunities to enhance the competitive advantage" with a mean (3.46) and a medium degree of evaluation, and the arithmetic average of the dimension as a whole was (3.73) with a high degree of evaluation.

\section{-Third, the findings of testing the study's hypotheses}

The main hypotheses: there is no statistically significant effect at the level of significance $(\alpha \leq 0.05)$ for management information systems in the financial performance of Islamic banks.

\section{Here are the second sub-hypotheses}

The first sub-hypothesis: there is no statistically significant effect at the level of significance $(\alpha \leq 0.05)$ for management information systems of profitability in Islamic banks. 
To verify the credibility of the first sub-hypothesis, the multiple regression was applied to study the impact of the dimensions of management information systems on the profitability equation.

Table 11. The results of the application of multiple regression analysis to study the impact of dimensions of management information systems on profitability

\begin{tabular}{|c|c|c|c|c|c|c|c|}
\hline Dimension & B & $\mathbf{T}$ & Level of significance & $\mathbf{R}$ & $\mathbf{R}^{2}$ & $\mathbf{F}$ & Level of significance \\
\hline $\begin{array}{l}\text { The system's ability to } \\
\text { provide information } \\
\text { security }\end{array}$ & 0.190 & 3.651 & 0.00 & 0.829 & 0.68 & 83.541 & 0.00 \\
\hline Speed of achievement & 0.364 & 5.756 & 0.00 & & & & \\
\hline $\begin{array}{l}\text { Simplifying } \quad \text { work } \\
\text { procedures }\end{array}$ & 0.132 & 2.277 & 0.023 & & & & \\
\hline
\end{tabular}

It appears from Table 11 the following:

1). There is a statistically significant effect at the level of significance $(\alpha \leq 0.05)$ to the ability of the system to provide information security to the proportion of profitability, the values $(\beta, T)$ reached $(0.190,3.651)$, respectively, which are statistically significant values.

$2)$. There is a statistically significant effect at the level of significance $(\alpha \leq 0.05)$ to the speed of achievement on profitability, the values $(\beta, T)$ reached $(0.364,5.756)$, respectively, which are statistically significant values.

$3)$. There is a statistically significant effect at the level of significance $(\alpha \leq 0.05)$ to simplify work procedures on profitability, the values $(\beta, T)$ reached $(0.132,2.277)$, respectively, which are statistically significant values.

4). There is a statistically significant effect at the level of significance $(\alpha \leq 0.05)$ to the dimensions of management information systems of profitability, as the value of the correlation coefficient $(R)$ was $(0.829)$ which is a statistically significant value which indicates the degree of statistical correlation between the independent variables and dependent variables, and the value of (R-square) was (0.68), which is a statistically significant value that explains the ability of management information systems to effect profitability, the value of $(F)$ was (83.541) with the statistical significance $(0.00)$, which is a statistically significant value at the significance level $(\alpha \leq 0.05)$ and this in turn indicates there is a statistically significant relationship between the independent variables and dependent variables, therefore, the hypothesis accepts the alternative formula and rejects the zero formula.

Sub-second hypothesis: there is no statistically significant effect at the level of significance $(\alpha \leq 0.05)$ for management information systems on the market share in Islamic banks.

To verify the validity of the second sub-hypothesis, it was used the multiple regression analysis to study the impact of dimensions of management information systems on the market share equation.

Table 12. The results of the multiple regression equation to study the impact of dimensions of management information systems on the market share

\begin{tabular}{llllllll}
\hline Dimension & $\mathbf{B}$ & $\mathbf{T}$ & Level of significance & $\mathbf{R}$ & $\mathbf{R}^{2}$ & $\mathbf{F}$ & Level of significance \\
\hline $\begin{array}{l}\text { The system's ability to provide } \\
\text { information security }\end{array}$ & 0.20 & 3.77 & 0.00 & 0.83 & 0.69 & 83.72 & 0.00 \\
Speed of achievement & & & & & & & \\
Simplifying work procedures & 0.35 & 5.74 & 0.00 & & & & \\
\hline
\end{tabular}

It appears from the Table 12 as follows:

5). There is a statistically significant effect at the significance level $(\alpha \leq 0.05)$ to the ability of the system to provide information security in the market share, the values $(\beta, T)$ reached $(0.2,3.77)$, respectively, which are statistically significant values.

6). There is a statistically significant effect at the significance level $(\alpha \leq 0.05)$ to the speed of achievement in the market share, the values of $(\beta, T)$ reached $(0.35,5.74)$, respectively, which are statistically significant values.

7). There is a statistically significant effect at the significance level $(\alpha \leq 0.05)$ to the dimension of simplifying 
work procedures for the proportion of market share, the values $(\beta, T)$ reached $(0.14,2.25)$, respectively, which are statistically significant values.

8). There is a statistically significant effect at the significance level $(\alpha \leq 0.05)$ to the dimensions of management information systems in the market share percentage, since the value of the correlation coefficient $(R)$ was $(0.83)$ which is a statistically significant which indicates the degree of function correlation statistically between the independent variable and dependent variable, and the value (R-square) was $(0.69)$ which is a statistically significant value that explains the ability of the dimensions of management information systems to affect the market share of the bank, the value of $(F)$ reached (83.72) with a statistical value $(0.00)$, which is a statistically significant value at the significance level $(\alpha \leq 0.05)$ which indicated a statistically significant relationship between the independent variable and dependent variables, therefore, the hypothesis accepts the alternative formula and rejects the zero one.

To verify the credibility of the main hypothesis, it was applied the multiple regression equation to study the impact of the dimensions of management information systems on the financial performance as a whole, Table 13 illustrates this.

Table 13. The results of the application of multiple regression equation to study the impact of the dimensions of management information systems as a whole on the financial performance

\begin{tabular}{|c|c|c|c|c|c|c|c|c|}
\hline Dimension & $\mathbf{B}$ & $\mathbf{T}$ & $\begin{array}{l}\text { Level } \\
\text { significance }\end{array}$ & of & $\mathbf{R}$ & $\mathbf{R}^{2}$ & $\mathbf{F}$ & $\begin{array}{l}\text { Level } \\
\text { significance }\end{array}$ \\
\hline $\begin{array}{l}\text { The system's ability to provide information } \\
\text { security }\end{array}$ & 0.22 & 3.80 & 0.000 & & 0.84 & 0.71 & 84.90 & 0.000 \\
\hline Speed of achievement & 0.38 & 5.79 & 0.000 & & & & & \\
\hline Simplifying work procedures & 0.15 & 2.22 & 0.000 & & & & & \\
\hline
\end{tabular}

It appears from Table 13 the following:

1). There is a statistically significant effect at the significance level $(\alpha \leq 0.05)$ to the ability of the system to provide information on the financial performance of security, reaching values $(\beta, T)(0.22,3.80)$, respectively, a statistically significant values.

2). There is a statistically significant effect at the significance level $(\alpha \leq 0.05)$ to the speed of achievement on the financial performance, the values $(\beta, T)$ reached $(0.38,0.38)$, respectively, which are statistically significant values.

3). There is a statistically significant effect at the significance level $(\alpha \leq 0.05)$ to the dimension of simplifying the procedures of work on the financial performance, the values $(\beta, T)$ reached $(0.15,2.22)$, respectively, which are statistically significant values.

4). There is a statistically significant effect at the significance level $(\alpha \leq 0.05)$ to the dimensions of management information systems at the financial performance, as the value of the correlation coefficient $(R)$ was $(0.84)$ which is a statistically significant value and this indicates the degree of statistically function correlation between the independent and dependent variables, The value of (R-square) was (0.71) which is statistically significant value and which explains the ability of the dimensions of management information to affect the financial performance of the bank, the value of $(F)$ was (84.90) and the statistical significance $(0.00)$, which is a statistically significant value at the significance level $(\alpha \leq 0.05)$ which indicated a statistically significant relationship between the independent variable and dependent variables, therefore, the hypothesis accepts the alternative formula and rejects the zero one.

\section{Results and Recommendations}

\subsection{Results}

Through the study and analysis of management information systems and their impact on the financial performance of the Islamic banks, and after making a statistical analysis on the relationship between the dimensions of management information systems and financial performance in the Jordan Islamic Bank, the study found a set of results including:

1) There is a statistically significant relationship between management information systems and financial performance in Islamic banks. 
2) There is a statistically significant relationship between the system's ability to provide information security and the financial performance of each of the profitability and liquidity in Islamic banks.

3) There is a statistically significant relationship between the speed of achievement and the financial performance of each of the profitability and liquidity in Islamic banks.

4) There is a statistically significant relationship between the simplification of work procedures and the financial performance of each of the profitability and liquidity in Islamic banks.

\subsection{Recommendations}

This study recommends the following depending on the results that have been achieved:

1) To strengthen information security procedures because of their significant role in improving the financial performance of Islamic banks.

2) To keep on continuous technological development in order to increase the speed of needed achievement, and thus it reduces as much of the client's time in carrying out duties and because of the impact on the speed of achievement and customers feedback which in turn will affect the financial performance of profitability and liquidity.

3) To simplify work procedures, so that they are simple and understood by customers and because of its impact on the financial performance.

\section{References}

Abdul, Q., \& Musharef. (2011). The role of strategic information systems in strengthening the competitive advantage (situation of Algerian institutions). Doctoral thesis, University of Algiers.

Ali, A. S. (2006). The entrance to knowledge management. Al Masira Dar for publication, Amman, Jordan

Azzawi, S. F. (2011). Job frustration and its impact on job performance. The Institute of Administration, Muscat, Oman

Chan, S. H. (2009). The roles of user motivation to perform a task and decision support system (DDS) effectiveness and efficiency in DSS use. Computers in Human Behavior, 25(1).

Da'as, A. A. A. (2010). A comprehensive management quality and its impact on improving the financial performance of applied study of a sample of Jordanian commercial banks Studies. Management Science, $37(1)$.

David, F. (2001). Strategic Management: Concepts \& Cases Strategic Management: Concepts \& Cases Management: Concepts \& Cases (8th ed.). Prentice HallInc: 100

Eccles, R. G. (1991). Performance Measurement Manifesto. Hurra Business review, 69(1).

Haag, S. C., \& Camming, M. (2000). Management Information Systems. Irwin MC Graw Hill.

Hamidi, N. (2005). Management Information Systems: A contemporary introduction. Publishing and Distribution, Amman, Jordan.

Holbeche, L. (2005). The high performance organization: Creating dynamic the high performance organization: creating dynamic stability and sustainable success. Elsevier Butterworth-Heinemann.

Hunt, S., \& Morgan, R. (1995). The Comparative Advantage Theory of competition. Journal of Marketing, 59, 6.

Kaur, B. P., \& Aggrawal, H. (2013). Exploration of success Factors of information system. International Journal of Computer Science, 10(1), 226-235.

Laudon, G., \& Laudon. (2007). Management Information System (7th ed.). Pearson, Education, New Jersey, USA.

Lynch, R. (2003). Corporate Strategy (4th ed.). Prentice-Hall, Inc.

Macmenamin, J. (1999). Financial Management (1st ed.). Rout ledge pub.

Miller, K. D., \& Bromiley, P. (1990). Strategic Risk and performance an analysis of Alternative Risk measures. Academy Management Journal, 33(4), 756-779.

O'Brin, J., \& Marks, G. (2004). Management, Information Systems (5th ed.).

Omary, G. I. (2012). The impact of information systems to achieve competitive strategies: A case study. Journal of Business and Economics. 
Petter, S., Delone, W., \& Mclean Ephraim R. (2013). Information Systems success: The quest for the independent variables. Journal of Management Information Systems, 29(4), 7-62.

Robins, J., \& Wiersema, M. F. (1995). A Resource Based Approach to multibusiness Firry Empirical Analysis of Portfolio Interrelationship and corporate Financial Performance. Strategic Management Journal, 16(4), 277-299.

Tashtosh, L. M. (2008). The role of information systems capabilities in promoting the strategies of a competitive advantage in the Jordanian industrial organizations. Unpublished master thesis. Al Albait University, Mafraq, Jordan.

Thompson, A. Jr. (1999). Strickland, Strategic Management: Concepts and Cases (9th ed.). Irwin.

\section{Copyrights}

Copyright for this article is retained by the author(s), with first publication rights granted to the journal.

This is an open-access article distributed under the terms and conditions of the Creative Commons Attribution license (http://creativecommons.org/licenses/by/3.0/). 